\title{
Design Website Portal Information Crime-Prone Location Using The Concept Of Crowdsourcing
}

\author{
Fairus Iqbal Maulana ${ }^{\mathrm{a}, 1,{ }^{*}}$, Choirul Huda ${ }^{\mathrm{a}, 2}$ \\ ${ }^{a}$ Computer Science Departement, School of Computer Science Bina Nusantara University, Indonesia \\ ${ }^{1}$ fairuz.maulana@binus.edu *; ${ }^{2}$ choirulhuda@binus.edu; \\ * corresponding author
}

\section{ABSTRACT}

Keywords

Web crime location Location base system Crowdsourcing
Collaboration between individuals or groups is also commonly referred to as mutual cooperation is a characteristic and culture of the Indonesian nation that is driven by the awareness that we are social beings. Mutual cooperation can be in the form of providing useful information for others. This information can be in the form of a report that is processed into data and displayed on the website. Information about the security of a crime-prone location is the main topic of our research. This study designed a website that collects information about crime-prone areas in a mutual cooperation or crowdsourcing and displays the data on a map-based website. Users can share information on crime-prone areas with location-based systems on the map. Data from user information will be accumulated and displayed on the map of a website. This data is visualized using a color circle. The darker colors indicate that the crime rate of the location is high. The system on the proposed website is very useful for users who travel to unknown areas.

\section{Introduction}

Rapid technological development, making the exchange of information faster and easier. With the advent of wireless broadband, the Internet can increase the activity of users to share and get information on the worldwide web. Users are connected to each other and can share their thoughts, pictures, videos and a position where they are with geographic information.

The development of internet technology that is getting faster and increasing internet users every year makes it easier to exchange information in cyberspace. The ease of information exchange is also supported by the development of mobile devices that are getting better. The development of smartphone technology makes it easier for users to obtain various kinds of information about a location. This information is collected from various users who can provide an assessment of the location. Suppose a user wants to visit a location or restaurant, the user can find out the address, photos, food menu, to the quality of the restaurant through information that has been given by other users. Location is the most important component in developing this website[1].

Location-based systems are increasingly being implemented in website development to date. This system can recommend a user's location to other users[2]. This information will greatly help a user who is traveling to a foreign area where the user has little or no information. The information provided by this system will be able to help many people[3].

This system will be applied to the website which is a national information disclosure to solve existing problems in society in mutual cooperation. This website is a momentum to solve the problem by empowering the community in order to build shared between the government, the public and stakeholders by promoting the spirit of mutual cooperation in the framework of selfsustainability toward a prosperous nation.

\section{The Proposed Method/Algorithm}

The way to be able to see the effectiveness of GIS technology in law enforcement is a good understanding of the techniques and the way in which they work[4]. For starters, there is a mathematical technique that can be used to help understand the data patterns, relationships and 
make projections. In the context of GIS and law enforcement, involving the analysis of statistical data interaction in a geographical setting. GIS system to process the crime rate history, incident reports today, the details of the deployment of personnel, vehicle travel route, prone locations, traffic patterns, recording cameras, and other variables which are then displayed on a map[5]. Practitioners then use these variables to the query to produce the results of the data analysis. Law enforcement can then look at the relationship of aggregate data for the geography of the city and also to observe trends, inferences and relationships at a local level[5].

Officials have a number of analytical methods. The following are three commonly used:

- Hot spots. A hot spot analysis refers to the time an event is sorted by geographic region. As a simple example, when displaying the frequency of reports of graffiti throughout the city, some blocks MIGHT show a greater incidence of graffiti beyond the rationale of higher population density. Typically, the display hot spots using a statistical method called cluster analysis, which separates data into logical groups.

- Correlation. In order to understand the patterns of crime through GIS, it is important to examine the correlation or how close two separate factors. Please note whether changes in the factors that lead to other changes, may indicate it appears the relationship between the factors, although the correlation alone does not prove a causal relationship.

- Regression. Regression analysis is one of the techniques that help discover the natural relationship between the characteristics of a person learns. If the hot spot showed where something happens and correlation indicates a clear causal link between these factors, regression show why by demonstrating of how these factors interact. Although regression is important, sometimes not every technique works because of some quirks in spatially related data.

GIS software has the ability to analytically rigorous and sophisticated. Has a lot of law enforcement officers and security that apply GIS in a number of ways. One of the goals is to use GIS to predict the location of a crime that might occur and immediately place the appropriate personnel to prevent crime. Another aim is to respond to the disaster. Official may combine the data information from officers in the field with other data such as from the agency or from social media[6].

\section{Method}

This website a breakthrough in the field of security technology on a location prepared to minimize the occurrence of repeated crime at that location[7]. This website is a pilot project that is proposed as a solution to the lack of information about the susceptibility of the crime scene in a city. In the design of the website system, each user is given the same rights to the features provided, ranging from crime-prone location information through Google Map view, the news about crime in every city, and security tips for users that can help minimize the possibility of becoming a victim of crime. Here is an explanation of the system requirements to achieve the objectives.

\subsection{System Analysis}

Analysis of the application system is aimed at identifying the problems that will arise in related aspects such as availability of reliable estimation and application performance, as well as data generated from within the system. This analysis will also identify whether the requirements have the appropriate information on the system. The information needs of the user or from the database.

Designing website portal prone crime location so that a criminal information media effectively done with the process of analyzing the existing needs, so we get the right result to be implemented in the system and the achievement of the objectives of the development of website portal prone crime location.

It required a great design from this website which can meet the needs that have been implied in the previous section. website portal prone crime location describes the relationship with the public via the media system that can be used to access information, but it also illustrates the application is available for various platforms. Besides the great design of this website describe the assets required to run the system, these assets including servers, databases and sources for data crawling. Here below is a great design from website portal prone crime location[8]. 
Photographs and greyscale figures should be prepared with 220 dpi resolution and saved with no compression, 8 bits per pixel (greyscale). Colour figures should be prepared with 400 dpi resolution and saved with no compression, 8 bits per pixel (palette or 256 colour) minimum.

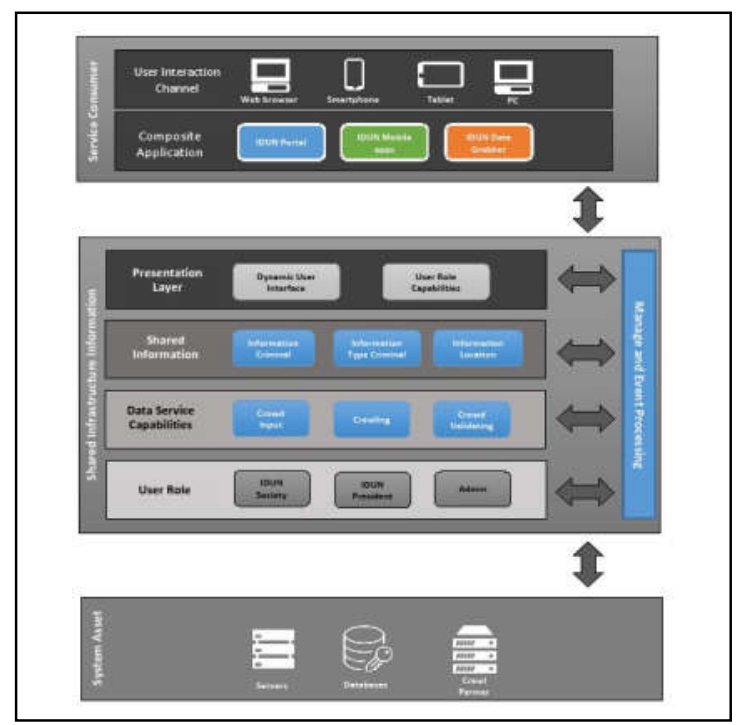

Fig. 1. Design website system portal prone crime location

This system design must be able to answer the needs of users of the system. In the manufacture of this system should obtain information acquisition. This website on two strategic acquisition of information, namely by using community participation (crowdsourcing) and mutual cooperation[9]. The following system requirements specification that is designed and constructed:

- This system is capable of recording user activity in the form of user reports on the crime scene to a public facility.

- This system will be integrated with Google Maps to facilitate users to find out information about the location of the user.

- This system will be integrated directly with local government agencies so that users can quickly accepted the report.

This system should provide clear information and can perceived by the user.

\subsection{Use Case Diagram}

Functional requirements described in this thesis by using use case diagrams. Use case diagram is one of the diagrams in UML to model the dynamic aspects of the system. Use case diagrams are used to model the behavior of a system, subsystem, or a class. Each diagram shows a set of use cases and actors and their relationships[6]. Here is a use case identified in website portal prone crime location. 


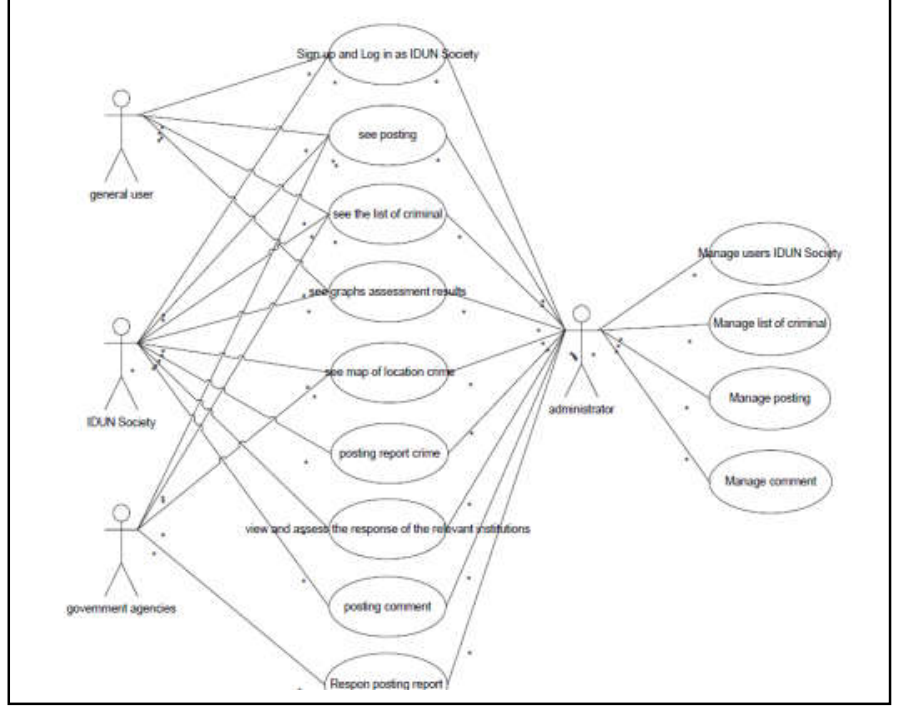

Fig. 2. Use Case Diagram website portal prone crime location

\subsection{System Architecture}

This website is designed to run on Windows-based server, the application server Internet Information Services (IIS). This websitecan be accessed anywhere, anytime through a web browser and internet.

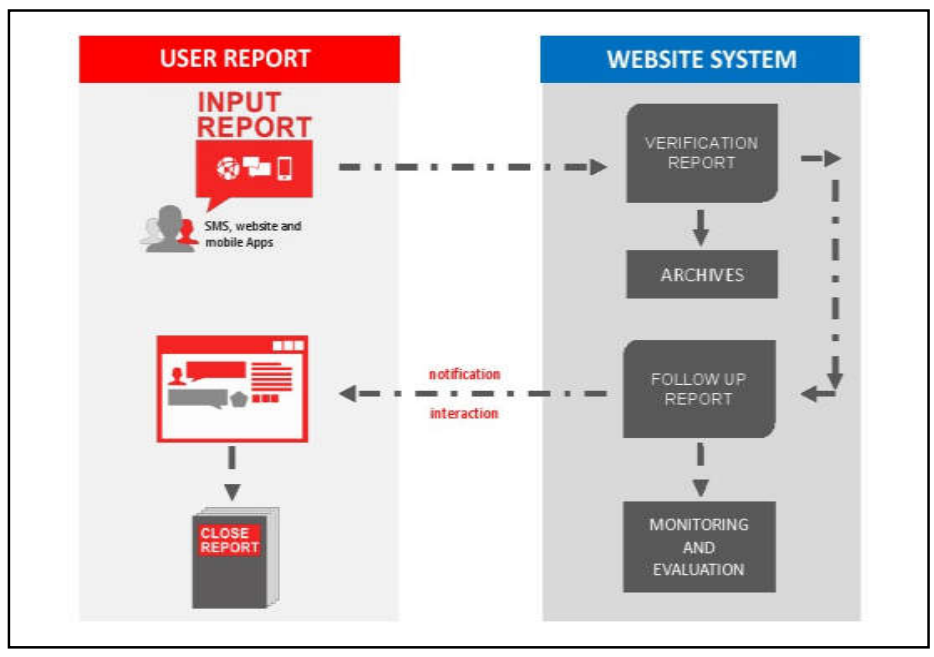

Fig. 3. System Architecture

\subsection{Architecture Diagram}

An activity diagram is a variation of a state machine, which is activity that represents the performance of an operation and the transition is triggered by the operation has been completed. Below can be described activity diagram of each scenario based on use case scenario. 


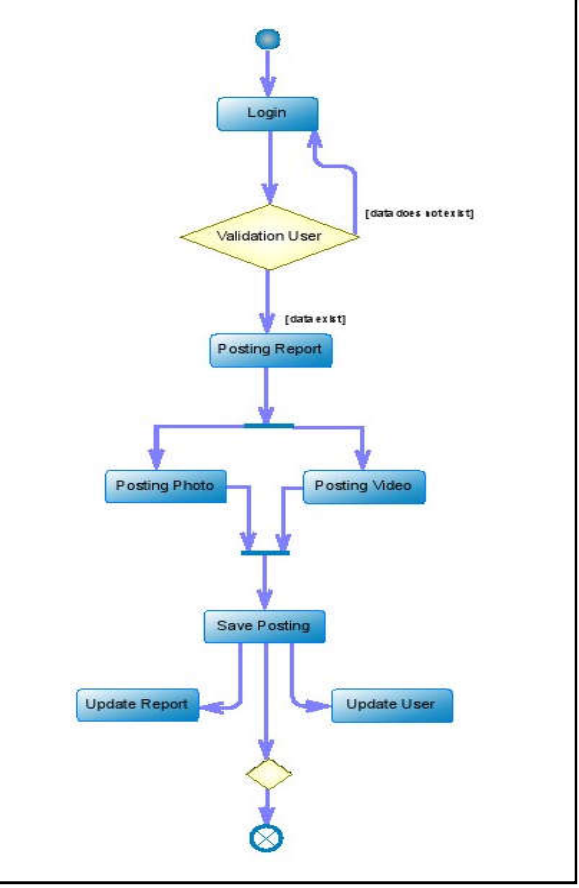

Fig. 4. Activity diagram post crine report

\subsection{Sequence Diagram}

A sequence diagram is the easiest way and moved by habits of a system by showing the interaction between the system and its environment. Here is a sequence diagram for the three main activities in the system.

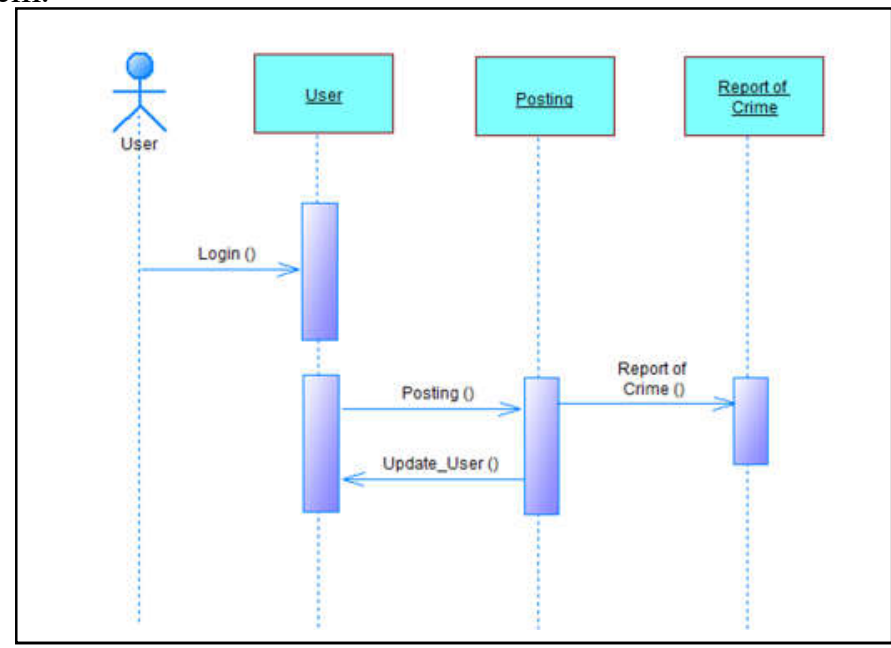

Fig. 5. Sequence Diagram post crime reports

\subsection{State Diagram}

State Diagram showing the sequence of activities of an object that has value and responds to generate stimulus and messages. This can be illustrated below state diagram of each activity based on use case. 


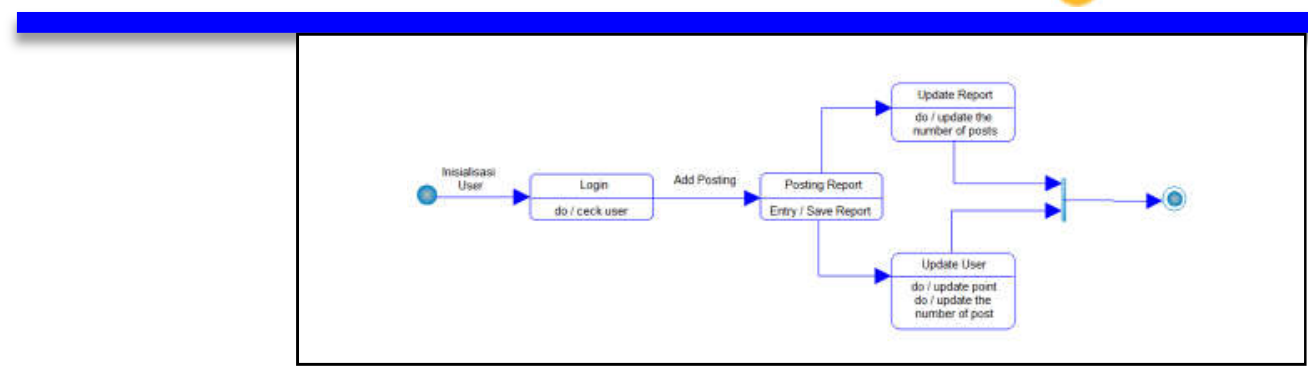

Fig. 6. State diagram post crime reports

\subsection{Gamification Design}

Application of the method gamification on crime reports are expected to be a new term known as gamification Crime Report[4]. Here, we will see if it is possible to apply gamification in the assessment process of reporting crime. Gamification Assessment Report Location Crime is an emedia methods gamification therein. Although there are several benefits in using gamification in the assessment process, there are also some disadvantages need to be considered.

Some disadvantages gamification in the assessment process the crime scene report are:

- Should be good in designing and implementing

- To be really in the process of maintenance

- be able to increase the production cost of the website/system

In addition to losses, some gains were known as gamification is used in the assessment system is a crime scene report:

- Can increase user satisfaction in knowing the crime-prone locations

- Can enhance user interaction with the government

- Can improve the performance of the government in making the city better

- Can reduce operational costs

By knowing the advantages and disadvantages of using gamification in the assessment process the crime scene report, can help gamification to get better results.

In principle, gamification has the ability to improve retention, attention and interaction between users and systems. Gamification components that will be applied in the design consists of four, namely:

- Rules: It is an order that is used as a foundation in a game, this rule is usually used to describe what can be done and not done by the user.

- Feedback: Feedback in the form of rewards obtained by the user when it has reached or accomplish something. Feedback is associated with the prizes and points, or comments from users.

- Goal: is the main thing that must be achieved by the user, and the goal can only be defined into two multiple and single only differs from the amount that must be achieved, typically when a user successfully achieves the goal of a game declared ended.

- Challenge: is a challenge to test the proficiency level of the user, and an important component in the creation of the game.

Based on these components, website portal prone crime location formed using gamification achievement approach, with component-based gamification framework. The design results in this website gamification is as follows:

Table 1. The Design Of The Gamification Of Website Prone-Crime Location

\begin{tabular}{ll}
\hline Rule: & Feedback: \\
$-\quad$ User action & - Reward \\
$-\quad$ Rules of the game & - User comments \\
\hline Goal: & Challenge: \\
$-\quad$ Gameplay & - Domain is use \\
$-\quad$ Objectives to beachieved & - Progress of players \\
& - Progres of report \\
\hline
\end{tabular}

This means that each component will affect each of the other components, at the point of designing gamification shall have a relationship, especially in the context of learning that can be taken by the user. In Indonesia in the context of the crime lot of learning to be conveyed to the 
users. For that gamification is no longer as packaging but rather to stimulate the role of the user in order to use the Website as a means of information.

\section{Results and Discussion of Website Design}

This service serves as initial information for the general user to be able to use the application. Web start page portal crime location consists of a map view crime-prone location and the latest news of the crime occurred.

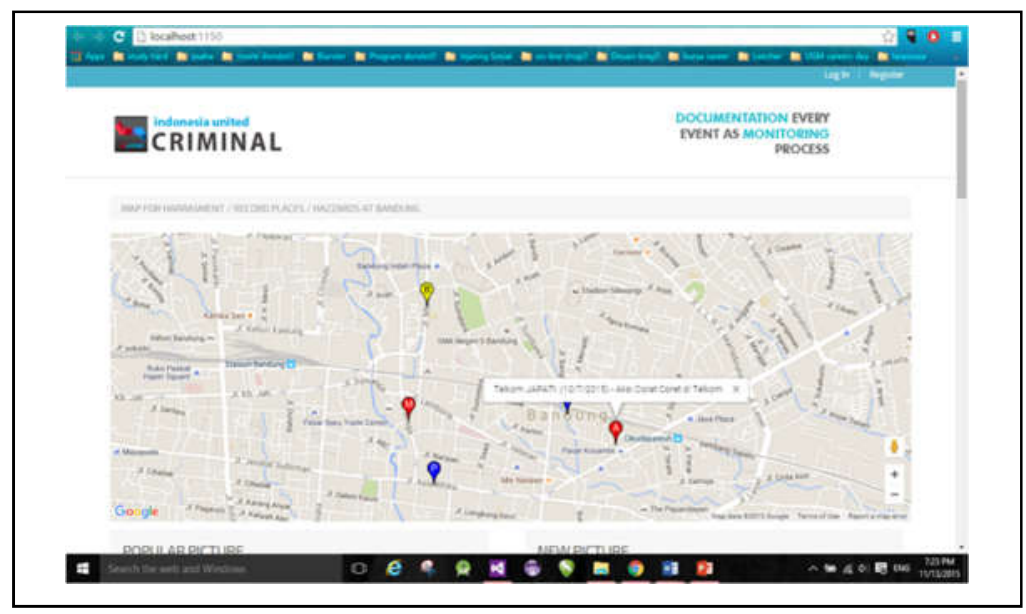

Fig. 7. Home of web portal crime location

In this website, user can upload photo and video, give comment, give like dislike with another user report and share the information to social media like Facebook, twitter and Google+. The result report from user already integrated with Google Map marker. This marker to show the location of crime report.

\section{Conclusion}

Author tries to implement a system-based location and Google Maps service to report and obtain information about the crime as well as information about public facilities damaged around us. What, when and where it happens, we can report and share information with other users. So, another user can be more alert to their surroundings. This system is expected to be a solution to the existing problems through cooperation between the user with mutual cooperation between governments, communities and stakeholders. The main objective of the design and implementation are designing the fulfillment media information about the crime-prone locations are open for people who need information in Indonesia. 


\section{References}

[1] Y. H. Park, "Relationship Analysis between Crime Types and Social Attributes in South Korea," Database Res., vol. 29, no. 2, pp. 81-94, 2013.

[2] J. Bao, Y. Zheng, and M. F. Mokbel, "Location-based and preference-aware recommendation using sparse geo-social networking data," in Proceedings of the 20th international conference on advances in geographic information systems, 2012, pp. 199-208.

[3] S. Scellato and C. Mascolo, "Measuring user activity on an online location-based social network," in 2011 IEEE Conference on Computer Communications Workshops (INFOCOM WKSHPS), 2011, pp. 918-923.

[4] G. Zichermann and C. Cunningham, Gamification by design: Implementing game mechanics in web and mobile apps. "O’Reilly Media, Inc.," 2011.

[5] J. D. E. Sandig, R. M. Somoba, M. B. Concepcion, and B. D. Gerardo, "Mining online gis for crime rate and models based on frequent pattern analysis," in Proceedings of the World Congress on Engineering and Computer Science, 2013, vol. 2, pp. 23-27.

[6] G. K. Habibullayevich, X. Chen, and H. Shin, "Efficient filtering and clustering mechanism for google maps," J. Adv. Manag. Sci., vol. 1, no. 1, pp. 107-111, 2013.

[7] A. Nasridinov, S.-Y. Ihm, and Y.-H. Park, "A decision tree-based classification model for crime prediction," in Information Technology Convergence, Springer, 2013, pp. 531-538.

[8] J. J. Levandoski, M. Sarwat, A. Eldawy, and M. F. Mokbel, "Lars: A location-aware recommender system," in 2012 IEEE 28th international conference on data engineering, 2012, pp. 450-461.

[9] W. Ahmad, A. Zia, and U. Khalid, "A Google Map based social network (GMBSN) for exploring information about a specific territory," 2013. 